\title{
Activities of the European Multiple Sclerosis Platform
}

\author{
Emma Rogan \\ Project Coordinator, European Multiple Sclerosis Platform, Brussels, Belgium
}

\section{Key Words}

Multiple sclerosis - European Multiple Sclerosis Platform .

Quality of life - Europe

\begin{abstract}
Background: The European Multiple Sclerosis Platform (EMSP) is an umbrella organization for national multiple sclerosis (MS) patients' associations in 34 European countries. Its focus is to improve the quality of life (QoL) of individuals with MS and inform society about the challenges of living with this chronic and debilitating disease. Summary: The EMSP, which is comprised of 39 MS societies across Europe, represents the interests of more than 600,000 individuals with MS and another 1.5 million persons affected by the disease, including family and caregivers. The organization works to achieve high quality, equitable treatment and support for persons with MS throughout Europe, as reflected in its main activities and projects. These include: the European Code of Good Practice in MS; a European MS register (EUReMS); a MS Barometer to assess QoL; the MS Nurse PROfessional curriculum to provide standards for MS nurse training; a photographic exhibition entitled Under Pressure; the Believe and Achieve project which focuses on employment for young people with MS; and collaboration in World MS Day, an inter-
\end{abstract}

national MS awareness day. Key Messages: The activities and projects of the EMSP are geared towards making a difference in the lives of individuals with MS in Europe and their wider support networks, including physicians, neurologists, nurses and carers.

(c) 2014 S. Karger AG, Basel

\section{Introduction}

Founded in 1989, the European Multiple Sclerosis Platform (EMSP; www.emsp.org) is the umbrella organization for 39 MS societies across 34 European countries [1]. The EMSP represents the interests of more than 600,000 individuals with MS and another 1.5 million person affected by the disease, including family and other caregivers, with the goal of delivering high-quality equitable treatment and support, as highlighted by its mission statements:

- To exchange and disseminate information relating to MS considering all issues relevant to the lives of people with MS.

- To encourage research of all kinds that is appropriate to people with MS, through recognized medical and other organizations.

\section{KARGER}

E-Mail karger@karger.com

www.karger.com/ene
(C) 2014 S. Karger AG, Basel

0014-3022/14/0721-0043\$39.50/0
Emma Rogan

MS Ireland

80 Northumberland Road, Ballsbridge

Dublin 4 (Ireland)

E-Mail emma.rogan@emsp.org 


\section{EMSP Mission}

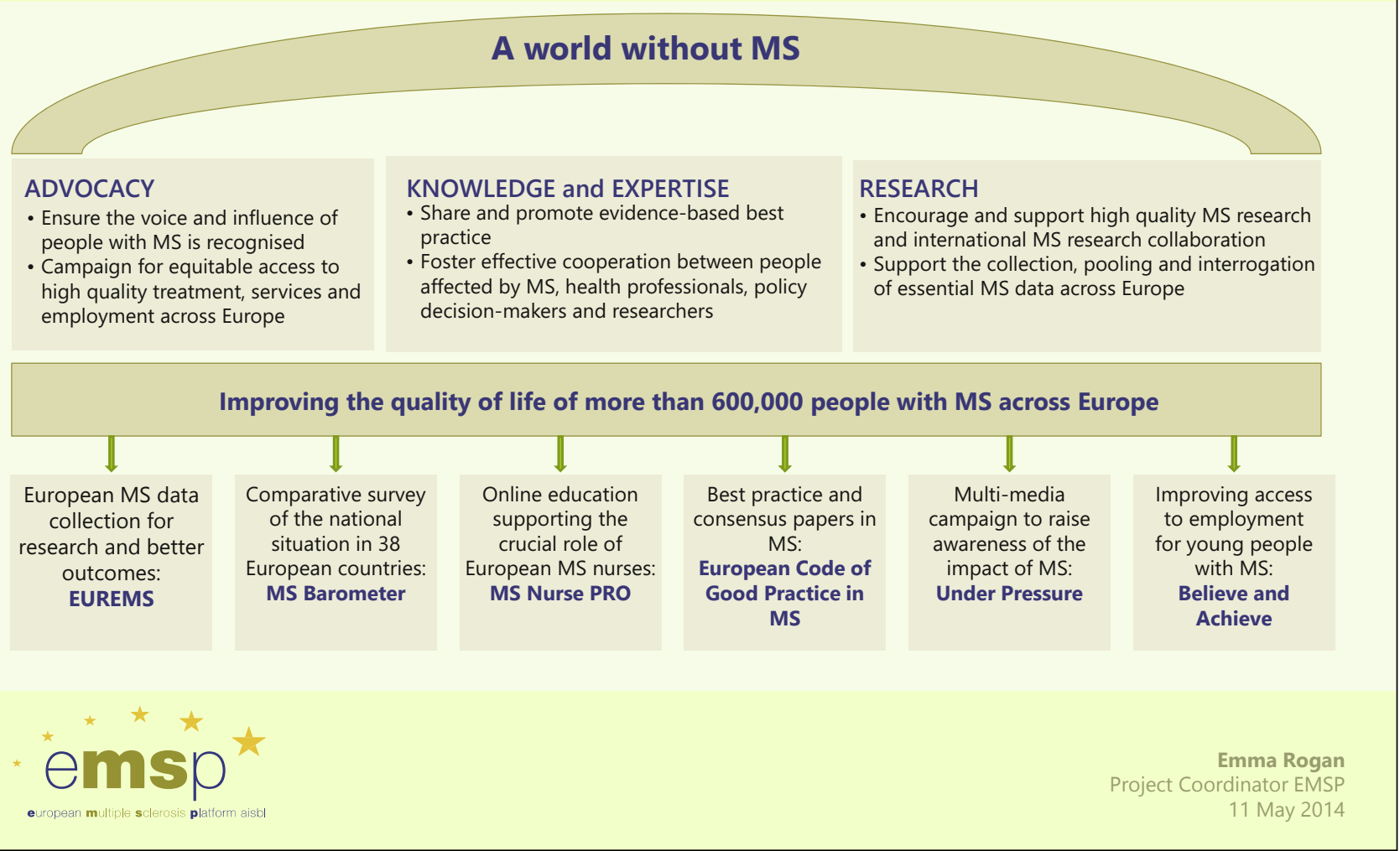

Fig. 1. The missions of the European Multiple Sclerosis Platform (EMSP).

- To promote the development of joint action programs with the participation of national MS societies in Europe, aiming at improving the quality of their activities and services.

- To act as a focal point for liaison with institutions of the European Union (EU), the Council of Europe, and other European organizations, in order to propose new measures to advance the rights of persons with disabilities and to ensure their full and effective participation in society.

\section{Activities and Projects}

The EMSP projects and activities encompass its vision and mission, and play a pivotal role in attaining goals such as improving the quality of life (QoL) of individuals with MS and responding to their expressed needs (fig. 1). Individuals with MS are enrolled by the EMSP on its member societies, staff and executive committee; these individuals and their carers constitute the EMSP and its activities.

\section{European Code of Good Practice in MS}

The European Code of Good Practice in MS (formulated through the European Parliament in 2003) promotes use of best practice, as supported by consensus papers in MS, to address discriminatory treatment towards people with MS. In addition, it promotes access to disease-modifying therapies, symptomatic treatments (e.g. for spasticity, bladder issues), palliative care and nursing, in accordance with the princi- 
pals of QoL as developed by the MS International Federation. Individuals with MS, and many other chronic illnesses, are subject to varying levels of medical and therapeutic care depending on where they live. Insufficient priority has been accorded by EU member states to remedy this situation. Whereas individuals with MS in some countries (e.g. Germany) receive excellent levels of care, whether medical or rehabilitative, the same level of care is not provided in other EU countries.

\section{EUReMS}

Collecting data on MS for research and better outcomes is fundamental to the work of the EMSP - if something can be measured, it can be changed. In 2011, only six national MS registries were identified despite the 600,000 individuals living with MS in Europe. The EMSP subsequently developed the European Register for MS (EUReMS), effectively enlisting and combining the expertise of clinicians, researchers and patient organisations [2]. Questions from patients, scientists, regulators and industry at an international level may be addressed by patient data collected nationally. Registry data also facilitate the efforts of patient advocates for improved access to evidence-based healthcare services, and provide further insights into the long-term effects of services offered and postmarking assessment of new therapies. The annual cost of MS to the EU is estimated at EUR 15 billion, and another EUR 5 billion is lost in productivity. Further information can be found at www.eurems.eu and http://www.europeanbraincouncil.org/pdfs/Publica tions_/Cost $\% 20$ of $\% 20$ Disorders $\% 20$ of $\% 20$ the $\% 20$ Brain \% 20in \% 20Europe $\% 20-\% 20$ economic $\% 20$ costs\%20-\%20EurNeuro2012.pdf.

\section{MS Barometer}

The MS Barometer is a benchmarking tool developed to obtain an accurate picture of the situation for individuals with MS across Europe via responses from clinicians and patients to key survey questions about obstacles and barriers. Topics addressed include: access to treatment and care; research; education, employment and job retention; involvement and empowerment; reimbursement of costs related to MS; data collection at the national level; and emerging treatments. The data sub- stantiate issues for politicians, healthcare staff, and wider society about the financial and human cost of living with MS.

\section{MS Nurse PROfessional}

MS nurses are fundamental to the health and welfare of individuals with MS. The MS Nurse PROfessional is an online, modular training curriculum developed several years ago to support the evolving role of European MS nurses in dealing with increasing numbers of patients, different treatments, and the challenges of patient care. The focus is on the core competency of MS nurses including advocacy, health education, and symptom and treatment management. The program also serves as a benchmark for MS nursing practice and care across Europe.

\section{'Under Pressure'}

'Under Pressure' is primarily a photographic project although films are also produced. Under Pressure provides a photojournalistic translation of the MS Barometer findings on inequalities in healthcare and social support in Europe, and is a high impact means of comparing the manner in which health and social policies alleviate or relieve the burden of MS across 11 EU countries. The project can be used as the basis to lobby for greater awareness and bring change for individuals with MS as it shows policy makers, and wider society, what it feels like to have and live with MS, and illustrates how QoL is affected.

\section{Believe and Achieve}

The Believe and Achieve project was launched in Dublin in mid-2014 to create employment opportunities for young individuals with MS through partnerships with European businesses. MS is diagnosed usually between 20 and 40 years of age - the prime working years of life. A pilot programme is underway aiming to have 10 employers take part and hire one individual on either a 6- or 12-month paid internship placement. The EMSP aims to raise awareness about employment issues for individuals with MS, provide information and support for them in their workplace and offer guidance for employers about staff retention. The EMSP intends to work with member organizations and the MS community to identify suitable partners and candidates. Along with these activities, an 
Employment Charter, focused on specific considerations for successful employment of people with MS or other neurological conditions is being developed. The project aims to highlight the benefits of tapping into the talent of enthusiastic, capable individuals with MS, while boosting career experiences and expectations.

\section{World MS Day}

The theme of World MS Day on 28 May 2014 was 'access'. This international MS awareness day is endorsed by the EMSP in Europe. Among the many issues highlighted on the day were access to employment, treatments, services, public transport, neurology services, rehabilitation, respect and recognition, dignity and relationships, as well as psychological state of mind and freedom for people with MS to live their lives.

\section{Conclusions}

By defining and addressing what it means to have a successful life despite living with a chronic neurological condition, the activities and projects of the EMSP aim to make a difference in the lives of individuals with MS and their wider support networks, including physicians, neurologists, nurses and carers.

\section{Disclosures/Conflict of Interest}

The author has no relevant affiliations or financial involvement with any organization or entity with a financial interest in or financial conflict with the subject matter or materials discussed in the manuscript.

Writing assistance was provided by Content Ed Net (Madrid, Spain), with funding from Laboratorios Almirall, SA (Barcelona, Spain).

\section{References}

1 The European Multiple Sclerosis Platform. http://www.emsp.org/.
2 The European Register for Multiple Sclerosis. http://www.eurems.eu/. 